\title{
As grandes potências e as economias emergentes no pós-crise
}

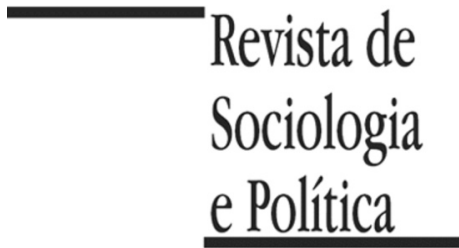

DOI: $10.1590 / 1678-987314225002$

\author{
Diego Santos Vieira de Jesus
}

Recebido em 09 de Julho de 2013. Aprovado em 09 de Agosto de 2013.

A crise econômico-financeira internacional iniciada em 2008 foi uma das crises mais severas desde a Grande Depressão. Teve início com a quebra de instituições nos Estados Unidos da América (EUA), que concediam empréstimos hipotecários de alto risco. Essa crise levou bancos para uma situação de insolvência e teve impacto sobre bolsas de valores por todo o planeta. Diante da crise de confiança geral no sistema financeiro e da falta de liquidez bancária, os governos buscaram agir de forma a mitigar os efeitos da crise. Entretanto, o grande acúmulo da dívida governamental motivou turbulência ao causar o receio de que tais governos não pudessem honrar os compromissos assumidos. Com a intensificação da crise, taxas muito mais altas eram colocadas para empréstimo. A indisciplina fiscal e o descontrole das contas públicas em Estados da Zona do Euro acabaram levando a União Europeia a um quadro generalizado de crise. As esperanças de uma rápida recuperação se mostraram estéreis, e se começou a perceber que a recuperação poderia levar mais tempo do que fora originalmente previsto. A União Europeia sofreu uma multiplicidade de crises, causadas especialmente pelo auxílio fiscal inadequado, instrumentos monetários tradicionais exauridos, desafios de insolvência e liquidez e falta de políticas de promoção de crescimento. Tais dilemas são complicados pelo processo fragmentado de formulação de decisão política e pelas falhas institucionais no processo de integração europeu. A deterioração da Zona do Euro colocou a China como um salvador em potencial. Tanto a China como os demais membros do BRICS - Brasil, Rússia, Índia e África do Sul - desejaram apoiar um importante parceiro comercial e uma fonte de tecnologia e investimento estrangeiro direto, mas inseriram condições para tal apoio. Como resultado, a União Europeia caminha na direção de uma redefinição de interesses e prioridades, que poderá afetar os interesses estratégicos dos EUA (Steinbock 2012).

No caso específico dos EUA, a crise fez com que a lacuna entre a retórica do presidente Barack Obama, com a aspiração a transformações fundamentais, e a precaução política tornasse-se mais explícita. Ela complicou as ações da administração Obama ao reduzir os recursos disponíveis a uma atuação internacional mais autônoma. Em face de suas limitações, o presidente buscou estabelecer uma nova ordem liberal em que os EUA preservavam sua liderança; entretanto, eles dividiriam responsabilidades e custos com outros Estados quando possível ou necessário. Na gestão da crise - que acabou tornando-se uma das suas prioridades - Obama buscou desenvolver ações coletivas urgentes com os membros do G8 e do G20 a fim de evitar que cada Estado buscasse a proteção de sua economia em prejuízo dos outros. Todavia, o papel dos EUA na precipitação da crise, com a popularização de instrumentos financeiros dú- 
bios, levou a questionamentos em torno do modelo de desregulação de mercados (Indyk, Lieberthal \& O'Hanlon 2012). Após o estouro da crise das hipotecas subprime, uma nova crise emergiu diante da desconfiança de que talvez os EUA não conseguissem honrar seus compromissos. A crise do teto de dívida norte-americana conduziu a um longo processo de discussão no Congresso Americano. Os principais pontos de debate incidiam sobre a realização do aumento e o montante, o que gerou dúvidas sobre a real capacidade de solvência dos EUA. Um acordo para a elevação do limite de gastos foi atingido em 2011, mas não teve a resposta positiva pelo mercado que tantas lideranças norteamericanas imaginavam.

Apesar da crise, a predominância dos EUA nas principais categorias do poder persiste como característica central do sistema internacional: a economia norte-americana, enorme e produtiva, permanece no centro do sistema econômico internacional, os princípios democráticos são partilhados pela maior parte dos Estados e as forças militares norte-americanas continuam as maiores quanto à projeção em teatros de operação distantes. Entretanto, alguns ajustes fizeram-se necessários, em particular no setor de defesa. Conforme foi destacado pelo próprio presidente Barack Obama, os gastos com defesa caíram diante da necessidade de pôr ordem na situação fiscal norte-americana e renovar sua força econômica. Na União Europeia, a suposição de que o euro fracassou em seu primeiro grande teste não tem fundamento. Contudo, a crise financeira e a recessão iluminaram problemas que poderiam surgir quando se tenta administrar um sistema de moeda única sem ter-se controle central decisivo da política econômica. Alguns dos principais desafios com os quais as grandes potências da Europa Ocidental deparar-se-ão serão as pressões dos EUA para que a União Europeia tenha uma maior contribuição militar na segurança internacional e europeia e o crescimento da força de Estados emergentes, em especial dos membros do BRICS (Brasil, Rússia, Índia, China e África do Sul) (Nugent 2010, pp. 448-451). Tais Estados defenderam uma arquitetura multilateral financeira e econômica reformada e mais democrática e apoiaram uma ordem mundial multipolar e equitativa, a reforma da ONU e as aspirações de Estados emergentes a um papel maior na organização e em outros fóruns e organismos multilaterais onde os EUA e as grandes potências da Europa Ocidental também atuam.

Diante do agravamento da crise financeira em nível global, investidores exigiram taxas muito altas para emprestar dinheiro a Estados europeus como a Grécia. A indisciplina fiscal e o descontrole das contas públicas na Zona do Euro acabaram acirrando o quadro de crise da União Europeia. Entretanto, tal crise tem raízes ainda mais profundas. Antes mesmo do começo da União Econômica e Monetária, o Tratado de Maastricht definia limites rigorosos para as finanças públicas dos Estados membros com base no reconhecimento da necessidade de políticas econômicas saudáveis dentro da união monetária. Porém, ao longo da última década, os limites foram pouco observados. Estados como a Grécia e a Irlanda registraram déficits públicos elevadíssimos, bem como Portugal e Espanha. A emergência de déficits enormes criou dificuldades para tais Estados no mercado financeiro, em especial para a Grécia. Esses Estados estavam seguindo trilhas insustentáveis que requereram a adoção de programas severos de austeridade. Ademais, a falta de disciplina macroeconômica em tais Estados deu origem a uma forte vulnerabilidade externa. Ao longo da década passada, uma política fiscal e monetária frouxa levou a uma inflação de salários e preços nesses Estados consideravelmente maior do que nos membros mais conservadores da União Econômica e Monetária, em ter- 
mos fiscais. A perda de competitividade aliou-se à performance cada vez pior na poupança no setor público. A essência da resposta da União Europeia à crise foi a tentativa de curar a dívida pública desses Estados periféricos e seus desequilíbrios externos pela busca de medidas severas de austeridade fiscal. Desde o começo da crise, a política da União Europeia foi orientada pelo princípio de condicionamento do auxílio à implementação de austeridade fiscal rigorosa. Esse foi o caso da maior parte dos programas de ajuda do Fundo Monetário Internacional (FMI) e da União Europeia para a Grécia, a Irlanda, Portugal e a Espanha. A austeridade fiscal também se colocou como um requisito para um possível movimento na direção de uma união fiscal e um apoio adicional do Banco Central Europeu. Um novo "pacto fiscal" foi adotado, comprometendo todos os membros da Zona do Euro a equilibrar seus orçamentos ao longo dos próximos anos; porém, isso não atenuou a incerteza do mercado quanto à habilidade política de os Estados em dificuldade manterem esse curso. O aprofundamento da recessão nos Estados em crise alimentou a crítica política contra a austeridade, manifesta na erosão da autoridade política dos partidos políticos tradicionais e na emergência de partidos populistas que se opõem ao euro. Ademais, o Banco Central Europeu pareceu fazer pouco para aliviar a recessão nessas economias (Lachman 2013).

Como a crise da dívida estava no topo da agenda política da União Europeia, o processo de integração teve menos tempo e energia para cuidar de sua política externa, de forma que faltaram ideias inovadoras sobre o front diplomático da União. As principais lideranças do bloco buscaram fortalecer as parcerias estratégicas com outras grandes potências e criar novas estruturas e prioridades de política externa em face das circunstâncias em transformação, mas, em face da pressão trazida pela crise, os chefes de Estado dos membros da União Europeia tiveram menos tempo e oportunidades para lidar com tais parcerias. Ademais, a crise da dívida ampliou as diferenças entre os Estados membros e enfraqueceu a coesão da União Europeia, de forma que seus membros procuraram dar mais atenção às suas próprias políticas externas. Após a entrada do Tratado de Lisboa em vigor, os membros fracassaram em transferir mais direitos soberanos para a União, como se esperava, e deram maior importância às suas relações bilaterais na busca de seus interesses. Ademais, a geoeconomia colocou-se no topo da agenda diplomática da União Europeia, com a segurança econômica tendo precedência sobre as demais dinâmicas de segurança. A União Europeia colocou maior importância aos ganhos econômicos relativos e ao controle de recursos pela combinação de setores públicos e privados para a obtenção de recursos e acordos econômicos por meio de negociações. Como resultado, o crescimento econômico em vez do desenvolvimento político tornou-se o principal condutor do processo de integração. Desde 2008, os Estados membros formularam novas regulações comerciais que eram discriminatórias em relação a Estados não-membros e empresas com elevados subsídios de exportação e práticas protecionistas. Ademais, a União Europeia estava preparada para reduzir o número de Estados que recebem benefícios de seu tratamento preferencial, particularmente retirando tal tratamento em relação a novas economias emergentes. O processo de integração não se mostrou mais tão colaborativo com outras regiões e Estados como no passado, apontando para uma maior necessidade de reciprocidade no relacionamento com os emergentes. Tal "reciprocidade" era, de fato, uma desculpa para o protecionismo da União Europeia de forma a extrair concessões de outros Estados. Finalmente, observa-se a redução substancial dos gastos de defesa do bloco, que prejudicam a condução da Política Comum de Segurança e Defesa (Longdi \& Youjin 2013). 
Apesar do sério impacto trazido pela crise, o nascimento de uma nova estrutura de integração após a entrada do Tratado de Lisboa em vigor trouxe uma nova vitalidade à política externa da União Europeia, que continuou a ampliar laços com alguns parceiros estratégicos e reajustou políticas em relação a Estados na vizinhança. Uma das tentativas da União de reforçar suas parcerias estratégicas foi a realização de uma série de reuniões bilaterais nesta década, em especial com membros do BRICS e o México. Ela também concluiu um acordo de livre comércio com a Coreia do Sul em 2010. Ademais, ela reajustou as relações com vizinhos a fim de promover prosperidade, estabilidade e segurança de todos os Estados. Tais ajustes ampliaram a visibilidade da União Europeia na Europa Oriental, no Sul do Cáucaso e no sul do Mar Mediterrâneo. A situação turbulenta na Ásia Ocidental e no Norte da África indica que a União Europeia depara-se com sérios desafios na sua vizinhança, o que oferece uma oportunidade para fortalecer sua política para os vizinhos. A revisão dessa política, feita em 2011, destacou a assistência, aos vizinhos, para a construção de democracias sólidas, o fortalecimento da cooperação política e na área de segurança e o apoio ao desenvolvimento socioeconômico sustentado em tais Estados, entre outros temas (idem).

Em uma perspectiva geral, a crise colocou obstáculos ao potencial da União Europeia de definir as questões globais. A preocupação dos Estados membros em negociar as modalidades de fundos de resgate e novas regras fiscais para a Zona do Euro consome muita atenção e recursos normalmente destinados à formulação das posições comuns de política externa da União Europeia e de suas estratégias diplomáticas. A influência global da União Europeia sempre pareceu ser uma função de dois elementos: seu status como modelo de área bem administrada e sua performance econômica superior. Entretanto, diante da crise, a União Europeia fracassou ao não manter os padrões de uma entidade bem governada e ainda há dúvidas sobre o efeito da crise sobre a performance econômica do bloco no longo prazo. A posição da União Europeia como um ator na política internacional sofreu o impacto da crise em duas formas significativas. Primeiramente, a crise diminuiu os recursos materiais disponíveis para a diplomacia da União Europeia em face das pressões orçamentárias crescentes. Ademais, a crise minou o poder de atração da União Europeia, cujos modelos sociais e econômicos eram concebidos como alternativas aos dos EUA e da China. A União Europeia parecia ser capaz de equilibrar justiça social e desenvolvimento sustentável. As deficiências do modelo econômico da União Europeia reduziram sua atração por outros Estados que agora mostram-se menos suscetíveis a endossar uma liderança por parte do bloco. Grande parte dos Estados membros do BRICS e do mundo em desenvolvimento consideram a União Europeia como um problema em vez de parte da solução, devido aos riscos que a crise na União Europeia traz para o crescimento econômico global. Muitos deles criticaram o pedido da União Europeia para que o FMI contribuísse para salvar a Grécia, enquanto Estados mais ricos membros do processo de integração não desejavam mobilizar mais esforços próprios diante da crise da Zona do Euro (ECFR 2012).

As três maiores potências do bloco - Alemanha, França e Reino Unido continuaram vendo as instituições multilaterais após a crise como meios de ampliar a participação na definição de regras e normas internacionais que atendam melhor aos seus interesses, reduzam as incertezas sobre o comportamento de outras grandes potências e permitam o exercício do poder de forma mais legítima e menos custosa sobre parceiros mais fracos. Embora o Reino Unido continue empenhando-se mais do que a França e a Alemanha em construir 
melhores relações com os EUA, o declínio relativo de tais grandes potências da Europa Ocidental após a crise tornou ainda mais evidentes os benefícios da cooperação com os EUA. Todas as três grandes potências da Europa Ocidental - em especial o Reino Unido - tornaram-se mais reticentes quanto ao aprofundamento do processo de integração na União Europeia após a crise, mas a França e a Alemanha buscaram preservar instituições mais autônomas. A liberdade de ação das três grandes potências da Europa Ocidental contrasta com o declínio gradual de sua influência global, de forma que sua ambição de servir, em parceria com os EUA, como árbitros em problemas internacionais foi gradativamente questionada por potências emergentes, bem como a ampla presença das potências da Europa Ocidental em organizações e processos internacionais. Assim, Alemanha, França e Reino Unido buscaram mobilizar seus recursos remanescentes consideráveis e, por meio de alianças com jogadores como Estados emergentes, manter-se ativas na política internacional.

Os membros do BRICS identificaram, no contexto da crise, a oportunidade para trazer demandas de participação mais ativa, dos Estados em desenvolvimento, na reforma das instituições financeiras internacionais, tais como o FMI e o Banco Mundial. O BRICS permitiu a seus membros mais espaço para o diálogo, a coordenação e a concertação em relação a múltiplos temas, bem como a ampliação de contatos e cooperação em setores específicos. Ele é sustentado pela vontade política de seus membros e caracterizado pela informalidade, tendo em vista a ausência de um documento constitutivo, um secretariado fixo e fundos para o financiamento de suas atividades. Entretanto, cabe destacar que, em face da gradativa intensificação dos laços entre os cinco Estados, veio aprofundando-se o grau de institucionalização do agrupamento. A maior institucionalização do agrupamento BRIC a partir da reunião ministerial de Ecaterimburgo, na Rússia, em 2008, implicou a criação de uma dinâmica de atividades conjuntas entre os quatro membros iniciais. As Cúpulas do BRIC/BRICS assumiram grande importância ao permitirem a intensificação da interação entre os membros. A primeira, ocorrida em Ecaterimburgo, em 2009, elevou a cooperação ao nível de chefes de Estado e Governo e defendeu uma arquitetura financeira e econômica reformada e mais democrática. $\mathrm{O}$ apoio do então BRIC - ainda sem a África do Sul - a uma ordem mundial multipolar e equitativa, à reforma da ONU e às aspirações de Brasil e Índia a um papel maior na organização foi reiterado na Cúpula de Brasília, em 2010. Apontando que a fundação da recuperação econômica mundial não era sólida, as lideranças reforçavam a necessidade de reforma das instituições financeiras internacionais e defendiam um sistema monetário mais previsível e diversificado, a proteção dos interesses dos Estados emergentes e a cooperação técnico-financeira na busca do desenvolvimento social sustentável. A Cúpula de Sanya, na China, em 2011, já contou com a participação da África do Sul e cobriu temas econômicos e financeiros e impulsionou projetos em agricultura, energia e ciência e tecnologia. O BRICS formulou um Plano de Ação que incluía o reforço dos programas existentes e novas áreas de cooperação e propostas. Com o objetivo de reforçar a parceria para a estabilidade, a segurança e a prosperidade globais, a Cúpula de Nova Deli, em 2012, englobou temas variados, como a gestão da crise econômica global; a reforma das instituições de governança econômica e financeira; meios de combate ao protecionismo; formas de se lidar com as questões síria e iraniana e a preocupação com desenvolvimento sustentável, ciência e tecnologia, urbanização, educação e saúde pública. Na Cúpula de Durban, em 2013, deu-se início às negociações do acordo para a criação de um novo banco de desenvolvimento liderado pelos cinco Estados e voltado para o financiamento de projetos de infraestrutura e desen- 
volvimento sustentável. Receberam destaque as discussões em torno de um fundo comum de reservas com o objetivo de socorrer os governos em caso de ameaça às contas externas. Os líderes do agrupamento também encontraram-se com lideranças regionais africanas em um diálogo em torno do tema "Liberando o potencial africano: a cooperação entre o BRICS e a África em infraestrutura". Porém, inúmeros itens da agenda permaneceram no âmbito de orientações gerais e imprecisas, sem avanços expressivos ou substantivos nas negociações multilaterais ou na resolução das crescentes disputas entre os próprios membros do agrupamento (Jesus 2013).

Os membros do BRICS identificaram, no contexto da crise, a oportunidade para trazer demandas de participação mais ativa, dos Estados em desenvolvimento, na reforma das instituições financeiras internacionais, tais como o FMI e o Banco Mundial. O BRICS permitiu a seus membros mais espaço para o diálogo, a coordenação e a concertação em relação a múltiplos temas, bem como a ampliação de contatos e cooperação em setores específicos. Ele é sustentado pela vontade política de seus membros e caracterizado pela informalidade, tendo em vista a ausência de um documento constitutivo, um secretariado fixo e fundos para o financiamento de suas atividades. Entretanto, cabe destacar que, em face da gradativa intensificação dos laços entre os cinco Estados, veio aprofundando-se o grau de institucionalização do agrupamento. A maior institucionalização do agrupamento BRIC a partir da reunião ministerial de Ecaterimburgo, na Rússia, em 2008, implicou a criação de uma dinâmica de atividades conjuntas entre os quatro membros iniciais. As Cúpulas do BRIC/BRICS assumiram grande importância ao permitirem a intensificação da interação entre os membros. A primeira, ocorrida em Ecaterimburgo, em 2009, elevou a cooperação ao nível de chefes de Estado e Governo e defendeu uma arquitetura financeira e econômica reformada e mais democrática. $\mathrm{O}$ apoio do então BRIC - ainda sem a África do Sul - a uma ordem mundial multipolar e equitativa, à reforma da ONU e às aspirações de Brasil e Índia a um papel maior na organização foi reiterado na Cúpula de Brasília, em 2010. Apontando que a fundação da recuperação econômica mundial não era sólida, as lideranças reforçavam a necessidade de reforma das instituições financeiras internacionais e defendiam um sistema monetário mais previsível e diversificado, a proteção dos interesses dos Estados emergentes e a cooperação técnico-financeira na busca do desenvolvimento social sustentável. A Cúpula de Sanya, na China, em 2011, já contou com a participação da África do Sul e cobriu temas econômicos e financeiros e impulsionou projetos em agricultura, energia e ciência e tecnologia. O BRICS formulou um Plano de Ação que incluía o reforço dos programas existentes e novas áreas de cooperação e propostas. Com o objetivo de reforçar a parceria para a estabilidade, a segurança e a prosperidade globais, a Cúpula de Nova Deli, em 2012, englobou temas variados, como a gestão da crise econômica global; a reforma das instituições de governança econômica e financeira; meios de combate ao protecionismo; formas de se lidar com as questões síria e iraniana e a preocupação com desenvolvimento sustentável, ciência e tecnologia, urbanização, educação e saúde pública. Na Cúpula de Durban, em 2013, deu-se início às negociações do acordo para a criação de um novo banco de desenvolvimento liderado pelos cinco Estados e voltado para o financiamento de projetos de infraestrutura e desenvolvimento sustentável. Receberam destaque as discussões em torno de um fundo comum de reservas com o objetivo de socorrer os governos em caso de ameaça às contas externas. Os líderes do agrupamento também encontraram-se com lideranças regionais africanas em um diálogo em torno do tema "Liberando o potencial africano: a cooperação entre o BRICS e a África em infraestru- 
tura". Porém, inúmeros itens da agenda permaneceram no âmbito de orientações gerais e imprecisas, sem avanços expressivos ou substantivos nas negociações multilaterais ou na resolução das crescentes disputas entre os próprios membros do agrupamento (Jesus 2013).

O BRICS conseguiu avançar na tradução de visões políticas em ações concretas, mas sua flexibilidade excessiva e a defesa da autonomia pelos seus membros podem dificultar posições coordenadas diante de desafios recentes. A governança e as reformas internas não acompanharam o crescimento econômico em muitos Estados do agrupamento. A opção pela informalidade e flexibilidade trouxe dificuldades na administração efetiva de percepções políticas divergentes e no estabelecimento de uma agenda cooperativa em novas áreas. A fórmula escolhida pelos membros conseguiu atender a alguns problemas de colaboração, mas não permitiu responder da mesma forma à grande parte dos desafios de estruturação de agendas sólidas na promoção do crescimento e de definição de posições unificadas em negociações externas. Alguns especialistas argumentam que, em determinadas questões, os membros sequer desejaram ou mesmo cogitaram administrar suas diferenças e divergências ou responder conjuntamente a diversos desafios. Diante da maior necessidade de ampliar os contatos oficiais e o trabalho com instituições internacionais, os Estados do BRICS deveriam atentar para a elaboração de uma fórmula jurídica que formalizasse seu estatuto e criasse uma plataforma institucional para a cooperação com tais organismos, bem como de instrumentos para a concretização de projetos multilaterais, inclusive em cooperação com outros Estados emergentes como a Turquia. Ademais, a diversificação de temas e atividades do agrupamento tornava fundamentais um órgão permanente de coordenação e a maior regularidade sobre a discussão acerca de novas ameaças (Davidov 2012).

O objetivo do dossiê "As grandes potências e as economias emergentes durante e após a crise econômico-financeira" é examinar o impacto da crise iniciada em 2008 sobre a atuação internacional das grandes potências e das principais economias emergentes, as formas como procuraram vencer os obstáculos trazidos por ela na busca de seus objetivos e suas principais linhas de atuação nas tentativas de superação da crise. Em meu artigo, procuro explicar a adoção da grande estratégia de acomodação pelos EUA durante a administração de Barack Obama para lidar com as principais ameaças a tal Estado no nível internacional e examinar os efeitos da crise econômico-financeira internacional iniciada em 2008 sobre a atuação internacional dos EUA. Com base na perspectiva analítica de Joseph S. Nye Jr. acerca do conceito de "poder inteligente", argumento que a adoção da grande estratégia de acomodação mostrou-se relacionada ao conceito de "poder inteligente" que informa as posições da administração Obama e que a crise não provocou um desafio fundamental à posição predominante dos EUA no sistema internacional, mas confirmou a necessidade de reajuste da grande estratégia de tal Estado na direção da acomodação dos interesses de grandes potências, economias emergentes e Estados hostis aos EUA. Entretanto, o reajuste da grande estratégia norteamericana não atingiu plenamente os resultados almejados por tal administraçao em face da cooperação limitada por parte de outras grandes potências, economias emergentes e Estados hostis aos EUA. Aponto que, ao complementarem seu poder militar e econômico com um investimento maior em seu poder brando, os EUA poderiam reconstruir a estrutura necessária para lidar com desafios globais.

A seguir, Kai Lehmann analisa a União Europeia e aponta que tratar sua crise atual exclusivamente como uma crise econômica não é só um equívoco, 
mas um risco para o desenvolvimento futuro da organização. O autor sustenta que a crise econômica simplesmente agravou uma crise de legitimidade pela qual a União Europeia está passando há algum tempo. Ele aponta que as tendências anti-europeias que estão espalhando-se pelos Estados europeus ameaçam o futuro do projeto de inntegração europeia e, em face disso, traz sugestões para reformas na atuação da União Europeia, particularmente a necessidade de elaborar-se um argumento coerente para justificar a continuação do projeto europeu. Lehmann também alerta para a necessidade de incorporação da população europeia no coração do processo político europeu em vez de somente se aplicarem medidas de austeridade.

Leonardo Ramos analisa a atuação das economias emergentes frente à crise e a articulação entre elas visando a superação de tal desafio, com uma ênfase na atuação do BRICS no âmbito do G20. O autor observa que, a partir de 2000, na cúpula de Okinawa, o sistema G7/8 começou um movimento de outreach, ou seja, tanto de "alcançar" aqueles que se encontravam fora quanto de "expandir" o sistema G7/8. Na cúpula de Gleneagles, em 2005, foi emitido um documento conjunto por Brasil, Índia, China, África do Sul e México (BICSAM) - Outreach Five ou Grupo dos Cinco (+5). Simultaneamente, desde 2008, o G20 vem lidando com tais questões como um fórum de líderes e, a partir de 2009, o então BRIC passa a se reunir como coalizão. O autor procura dar atenção às potências médias emergentes - em especial à China e aos demais membros do BRICS -, suas coalizões e formas de engajamento e articulação no âmbito do G20, bem como analisar as potencialidades e os limites dessas iniciativas.

Tratando mais especificamente do caso brasileiro, Igor Abdalla aponta como os novos teóricos liberais negligenciaram as assimetrias inerentes à globalização e argumenta que a globalização financeira foi resultado da mobilização maciça de poder por uma constelação de forças hegemônicas que condicionou a visão de mundo dos técnicos em política econômica. A partir daí, Abdalla estuda as crises financeiras nos Estados emergentes tendo como base o caso emblemático da Argentina, de forma a explorar como a adoção dogmática do receituário dominante do novo liberalismo econômico criou obstáculos ao estancamento da crise. O autor reconhece que a Grande Recessão que eclodiu em 2008 acentuou a ascensão do Sul Global e deslocou o epicentro da governança global para novos fóruns, como o G20. Em tal contexto, abremse possibilidades para que Estados em desenvolvimento - em especial o Brasil - desenvolvam uma política externa crítica, resgatando o elemento emancipatório do liberalismo kantiano.

Arindan Banik e Fernando Padovani exploram o modelo do "novo crescimento" indiano e sua inter-relação com setores específcos da sociedade indiana, o Estado, a agricultura e as dinâmicas de inserção internacional. Os autores procuram averiguar as condições e perspectivas de sustentabilidade econômica do modelo de crescimento em curso, considerando também os desafios imediatos colocados pela crise econômico-financeira internacional. Eles apontam para a existência de condições concretas de sustentabilidade econômica do modelo indiano, baseada na perspectiva de expansão de seus setores dinâmicos, como o setor de exportação de serviços tecnológicos e de manufaturas destinadas ao mercado interno. Evoluções paralelas relacionadas à transição demográfica, à disponibilidade interna de poupança e de investimento, ao crescimento das novas classes médias, às perspectivas de continuidade de oferta de investimentos estrangeiros e de conexão com as cadeias produtivas globais, além da identificação de dinâmicas sociais de transformação e adaptabilidade, 
reiteram a existência de condições de sustentabilidade do atual modelo de crescimento. Entretanto, não se trata de uma sustentabilidade sem riscos, ao serem identificados também desafios de percurso importantes, como a viabilização dos importantes investimentos em infraestrutura, educação e inovação, capazes de garantir as necessárias condições de estabilidade, absorção de mão de obra, crescimento equitativo, oferta de mão de obra qualificada e inovação, além de segurança alimentar.

Finalmente, Aylin Gurzel analisa a capacidade de projeção de poder da Turquia no nível regional no contexto de superação dos efeitos da crise financeira e de rápido crescimento econômico. A autora argumenta que uma potência regional como a Turquia deve desenvolver capacidades econômicas, diplomáticas e organizacionais. Tais elementos precisam ser reconhecidos pelos demais atores no nível da região e também pelas grandes potências e potências emergentes que são determinantes da dinâmica da política internacional. Nesse contexto, a Turquia busca não somente melhorar suas relações com o Sul do Cáucaso, os Bálcãs e o Oriente Médio, mas também com os EUA, a União Europeia e Estados emergentes como o Brasil e a China.

Diego Santos Vieira de Jesus (dvieira@espm.br) é doutor em Relações Internacionais pela Pontifícia Universidade Católica do Rio de Janeiro (PUC-Rio) e professor do curso de Graduação em Relações Internacionais da Escola Superior de Propaganda e Marketing do Rio de Janeiro (ESPM-RJ).

\section{Referências}

Davidov, V. 2012. Brics em busca de um novo equilíbrio mundial. Gazeta Russa, 10.mar. Disponível em: http://gazetarussa. com.br/articles/2012/03/10/brics_em_busca_de_um_novo_equilibrio_mundial_14293.html. Acesso em: 9.jun.2014.

Indyk, M.S.; Lieberthal, K.G. \& O'Hanlon, M.E. 2012. Scoring Obama's Foreign Policy. Foreign Affairs, 91(3).

Jesus, D.S.V. 2013. De Nova York a Durban: o processo de institucionalização do BRICS. Oikos, 12(1), pp. 32-62.

Lachman, D. 2013. Lessons from Europe's Debt Crisis for the United States. AEI, 6.June. Disponível em: http://www.aei.org/ article/economics/international-economy/lessons-from-europes-debt-crisis-for-the-united-states/. Acesso em: 9.jun.2014.

Longdi, X.; Youjin, S. 2013. The EU's Foreign Policy Under Debt Crisis. China Institute of International Studies, 5.Mar. Disponível em: http://www.ciis.org.cn/english/2013-03/05/content_5774751.htm. Acesso em: 9.jun.2014.

Nugent, N. 2010. The Government and Politics of the European Union. $7^{\text {th }}$ ed. New York: Palgrave Macmillan.

Steinbock, D. 2012. The Eurozone Debt Crisis: Prospects for Europe, China, and the United States. American Foreign Policy Interests, 34(1), pp. 34-42.

\section{Outras fontes}

ECFR. 2012. European Foreign Policy between Debt Crisis and Renationalisation. Ideas on Europe, 28.Feb. Disponível em: http://ecfr.ideasoneurope.eu/2012/02/28/european-foreign-policy-between-debt-crisis-and-renationalisation/. Acesso em: 9.jun.2014. 